\title{
Grondsoort en grondprijs
}

November 2016

Huib Silvis, Martien Voskuilen (Wageningen Economic Research)

Paul Peter Kuiper (Kadaster) en Everhard van Essen (Aequator)

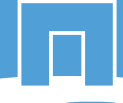

WAGENINGEN

UNIVERSITY \& RESEARCH

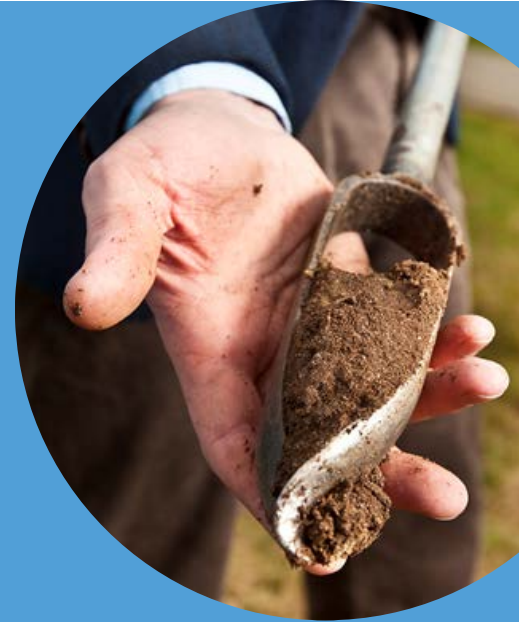

Grondpercelen met lichte en zware zavel en lichte klei noteren de hoogste gemiddelde prijzen. De specifieke gebruiksbeperkingen van zand en zware klei zorgen ervoor dat de percelen met deze grondsoorten veelal lager geprijsd zijn. Percelen met grondsoorten veen en moerig op zand hebben de laagste gemiddelde agrarische grondprijs. Hoe zijn deze verschillen te verklaren en in hoeverre bepalen ze de regionale grondprijzen?

\section{Grondsoort en landelijke grondprijs}

De belangrijkste grondsoorten in Nederland zijn zand (48\%), zavel (licht en zwaar, 22\%), klei (licht en zwaar, $17 \%$ ) en veen ( $9 \%$ ) (tabel 1 en kaart 1 ). Verder zijn nog onderscheiden moerig op zand ( $2 \%$; in hoofdzaak in het Noorden en Oosten van het land) en leem (2\%; in hoofdzaak in Zuid-Limburg). De gemiddelde agrarische grondprijs per grondsoort loopt (gemiddeld over de jaren 2012-augustus 2016) uiteen van circa 43.000 euro per ha voor moerig op zand en veen, 51.000 à 54.000 euro op zware klei, zand en leem, tot 57.000 à 58.000 euro op lichte zavel, lichte klei en zware zavel (tabel 1). De prijsverschillen worden voor een deel veroorzaakt door de landbouwkundige geschiktheid van de verschillende grondsoorten (zie kader).

Landbouwkundige bodemgeschiktheid

De bodemgeschiktheid voor de landbouw wordt sterk bepaald door grondsoort en grondwaterstanden. Uit de grondsoort of bodemopbouw (zie verantwoording), en de grondwatersituatie wordt een aantal zogenaamde beoordelingsfactoren afgeleid, zoals ontwateringstoestand, vochtleverend vermogen, draagkracht, bewerkbaarheid en slempgevoeligheid. Bij de landbouwkundige bodemgeschiktheid wordt onderscheid gemaakt naar geschiktheid voor grasland en akkerbouw. Akkerbouwmatig gebruik stelt hogere en bredere eisen aan de grond dan grasland, bijvoorbeeld een diepere ontwatering.

De voor landbouw meest geschikte gronden zijn goed ontwaterde lichte en zware zavelgronden. Deze leveren de hoogste opbrengsten en hebben de minste beperkingen. Daarna volgen de lichte kleigronden; ze zijn minder goed bewerkbaar dan de zavels door het hogere lutumgehalte ('zwaarder'), en veelal is de draagkracht iets beperkter. Daardoor zijn ze ook minder geschikt voor hoog salderende gewassen zoals peen. Ook is bekend dat opbrengsten en sortering van pootgoedaardappelen op lichte kleigronden iets minder zijn dan beter bewerkbare lichte en zware zavelgronden.

Zandgronden zijn altijd goed bewerkbaar en slempgevoeligheid speelt geen rol. De grootste beperking is veelal stuifgevoeligheid en, afhankelijk van de grondwaterstand, het vochtleverend vermogen. Met name zandgronden met een dunne, humeuze bovengrond en diepe grondwaterstanden (zonder capillaire nalevering) zijn droogtegevoelig.

Veengronden hebben over het algemeen een minder goede ontwateringstoestand door de hoge grondwaterstanden en een minder goede draagkracht. Deze gronden zijn meestal alleen geschikt voor grasland. 
Tabel 1 Oppervlakte en agrarische grondprijs naar grondsoort

\begin{tabular}{|c|c|c|c|}
\hline & $\begin{array}{r}\text { Oppervlakte a) } \\
\text { (ha) }\end{array}$ & $\begin{array}{r}\text { Oppervlakte } \\
(\%)\end{array}$ & $\begin{array}{r}\text { Grondprijs b) } \\
\text { (euro/ ha) }\end{array}$ \\
\hline Lichte zavel & 324.498 & 10,5 & 57.100 \\
\hline Zware zavel & 345.171 & 11,2 & 58.200 \\
\hline Lichte klei & 290.875 & 9,5 & 58.100 \\
\hline Zware klei & 230.483 & 7,5 & 51.000 \\
\hline Veen & 290.010 & 9,4 & 42.900 \\
\hline Moerig op zand & 71.679 & 2,3 & 42.600 \\
\hline Zand & 1.465 .988 & 47,7 & 51.600 \\
\hline Leem & 57.359 & 1,9 & 53.600 \\
\hline Nederland & 3.076 .063 & 100,0 & 52.500 \\
\hline
\end{tabular}

a) Bron: Grondsoortenkaart 2006, Wageningen Environmental Research; b) Gemiddelde agrarische grondprijs 2012-augustus 2016; Bron: Kadaster, RVO en Wageningen Economic Research.

\section{Grondsoort en regionale grondprijs}

Het landelijke patroon van een oplopende grondprijs in de reeks veen - zand/zware klei - zavel/lichte klei, geldt in het algemeen ook voor de groepen van landbouwgebieden (figuur 1). In enkele gebieden wijkt het beeld echter wel af van het landelijke. Dat geldt vooral voor de zandgronden die in het Centraal en Zuidelijke Veehouderijgebied, het Rivierengebied en Zuidwest-Brabant (bijna) de hoogste grondprijzen noteren.

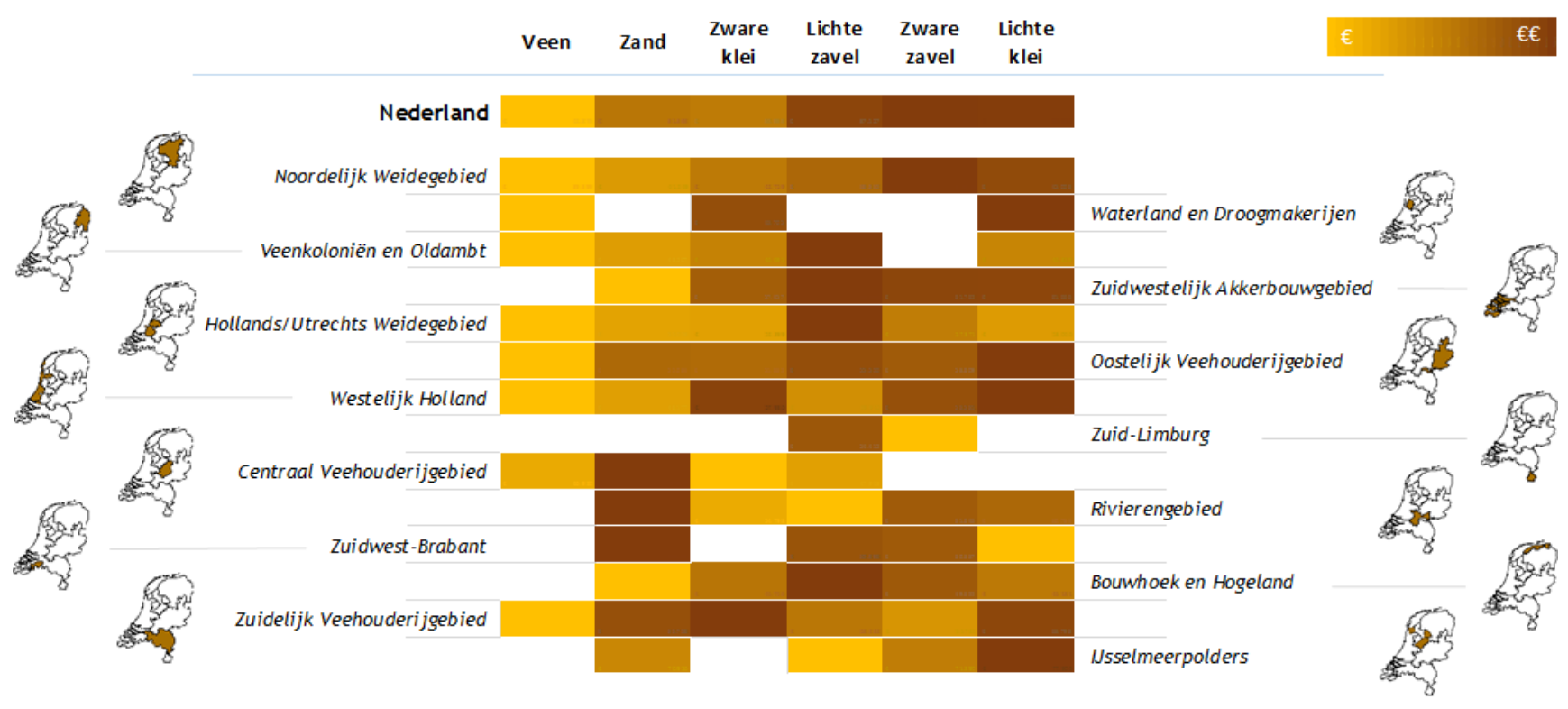

Figuur 1 Agrarische grondprijsverschillen naar grondsoort en landbouwgebied a)

a) Per CBS-landbouwgebied zijn met een kleurcodering prijsverschillen weergegeven. Gebaseerd op de grondmarktgegevens van 2012 augustus 2016 (Kadaster/RVO/Wageningen Economic Research) en de grondsoortenkaart 2006 (Wageningen Environmental Research). De grondsoorten leem en moerig op zand ontbreken door het geringe aantal waarnemingen.

\section{Grondsoort als prijscomponent}

Grofweg zijn de grondprijzen in het Zuiden en de IJsselmeerpolders het hoogst en in het Noorden het laagst (1e kolom tabel 2). In de tweede kolom is het verschil met de landelijke grondprijs vermeld. In hoeverre vallen de prijsverschillen samen met de grondsoortsamenstelling? In de 3e kolom staat de grondprijs op basis van de grondsoorten in het gebied. Dat is een fictieve prijs door de gemiddelde Nederlandse grondprijs per grondsoort (zie tabel 1) toe te passen op de aanwezige grondsoorten. Het verschil tussen die grondprijs en de gemiddelde Nederlandse grondprijs wordt het grondsoorteffect genoemd (4e kolom). De grondprijs op basis van de grondsoorten komt niet overeen met waargenomen grondprijs. Die 'restcomponent' (5e kolom tabel 2 ) moet verklaard worden door andere factoren dan de grondsoort. 
Tabel 2 Grondprijs a) en prijscomponenten (alle in euro/ha) naar landbouwgebied

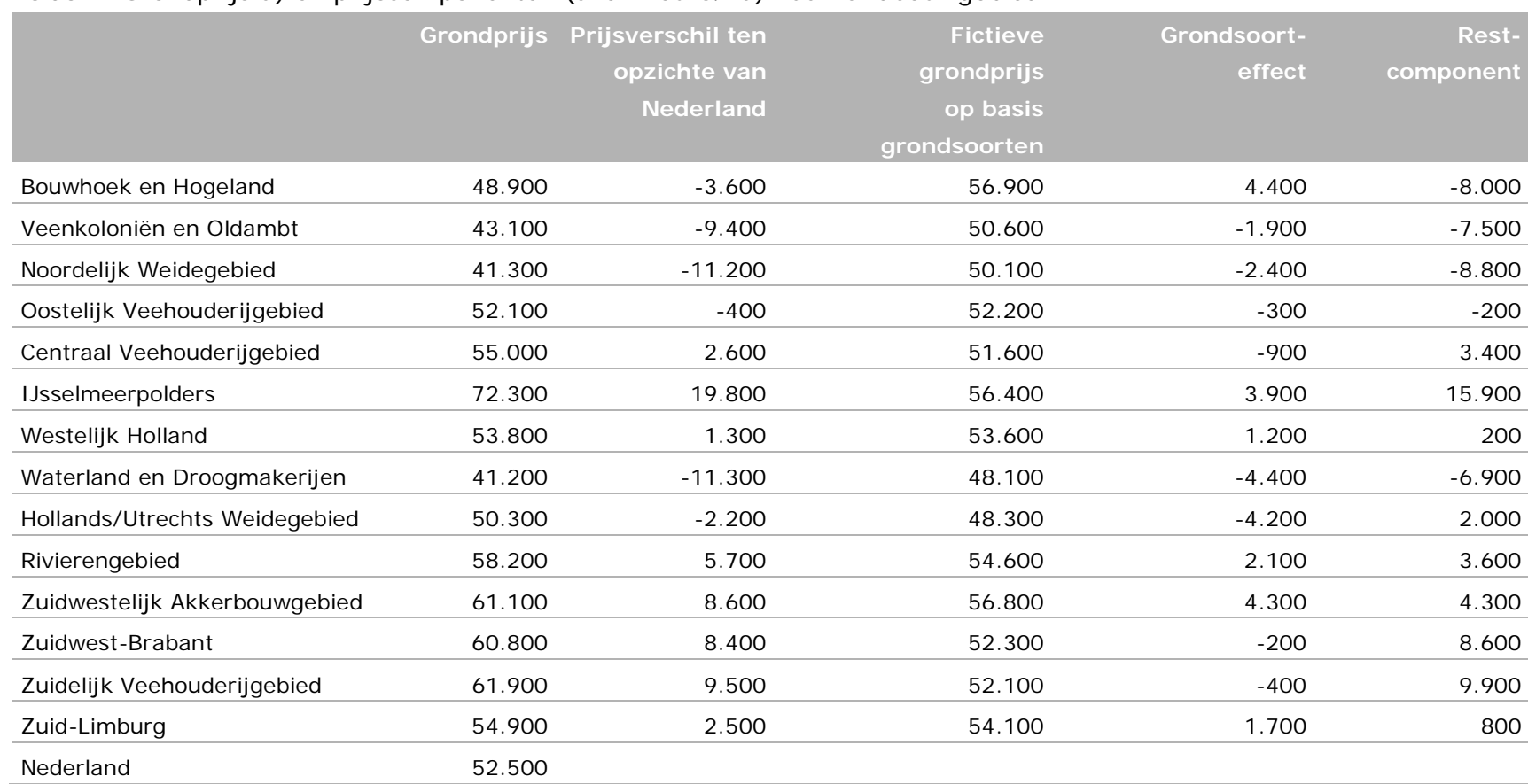

a) Gemiddelde 2012-augustus 2016.

Bron: Kadaster, RVO en Wageningen Economic Research.

De gemiddelde agrarische grondprijs in de periode 2012-augustus 2016 loopt uiteen van 41.200 euro in Waterland en Droogmakerijen tot 72.300 euro per ha in de IJsselmeerpolders ( 1 e kolom tabel 2). Een verschil van 31.100 euro, ofwel $75 \%$. Het verschil met de fictieve, op basis van de grondsoorten berekende grondprijs, is nog maar 8.800 euro, ofwel 18\%. De grootste verschuivingen in de rangschikking naar hoogte van de grondprijs is die van Bouwhoek en Hogeland (van plek 11 naar plek 1) en het Zuidelijk Veehouderijgebied (van plek 2 naar 9 ).

Het grondsoorteffect is het meest positief in Bouwhoek en Hogeland, IJ sselmeerpolders en het Zuidwestelijk Akkerbouwgebied. Dat is te danken aan het zeer hoge aandeel (meer dan $80 \%$ ) van de 'duurdere' grondsoorten lichte en zware zavel en lichte klei in deze landbouwgebieden. Het meest negatief is het grondsoorteffect in Waterland en Droogmakerijen en het Hollands/Utrechts Weidegebied, gebieden met veel (circa de helft) relatief goedkope veengrond.

Voor de IJ sselmeerpolders is in deze benadering het grondsoorteffect 3.900 euro per ha positief, en de restcomponent bijna 16.000 euro per ha in de plus. Dat zal naast de overige gunstige productie- en afzetomstandigheden, vooral veroorzaakt worden door de bedrijfsstructuur, dat wil zeggen grotere, intensievere bedrijven met een hogere verdiencapaciteit dan in de rest van het land.

Ook in het Zuiden is de restcomponent positief. Hierbij valt te denken aan de omvang van de bedrijven, mestafzet en de intensiteit van het grondgebruik. Dat kan binnen een sector zijn, zoals binnen de melkveehouderij (die in het Zuiden intensiever is), en door de aanwezigheid en concurrentie met andere intensieve sectoren zoals de tuinbouw.

Het 'grondsoorteffect' en de 'restcomponent' zijn overigens niet strikt te scheiden, omdat bijvoorbeeld verschillen in plaatselijke omstandigheden, zoals ligging bij grote steden en schaarste, kunnen leiden tot verschillen in prijzen voor dezelfde grondsoort. 


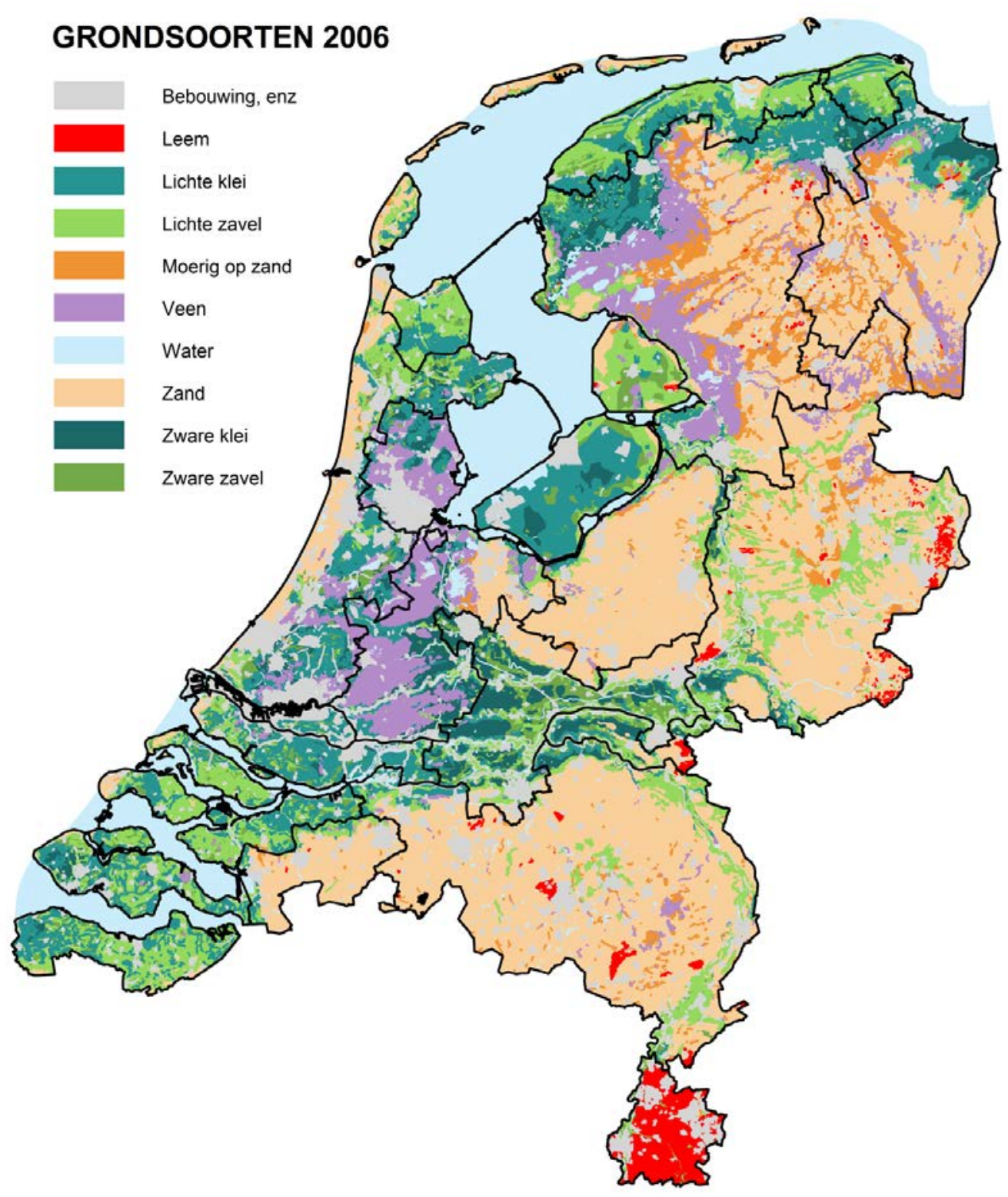

Kaart 1 Grondsoorten en grenzen landbouwgebieden (14 groepen van landbouwgebieden) Bron: Grondsoortenkaart 2006, Wageningen Environmental Research; 14 groepen van landbouwgebieden, CBS.

\section{Kanttekeningen en beperkingen}

De analyse in dit bericht is een globale benadering, waarbij de volgende kanttekeningen passen:

- De indeling in acht grondsoorten is een sterke vereenvoudiging van de bodemopbouw, waardoor prijsverschillen binnen een grondsoort worden weggemiddeld.

- Grondwaterstanden zijn niet meegenomen; deze bepalen mede de bodemgeschiktheid.

- Door technologische ontwikkelingen zijn de beperkingen van een aantal grondsoorten voor een belangrijk deel weggenomen (of weg te nemen).

- De bodemvruchtbaarheid of bemestingstoestand - nutriëntentoestand (stikstof, fosfaat en kali) en pH-waarde - speelt in het bepalen van de bodemgeschiktheid geen rol omdat verondersteld wordt dat die op orde is.

- De grondsoorten die het meest geschikt zijn voor landbouwkundig gebruik, zijn bruikbaar voor zowel akkerbouw als grasland (melkveehouderij) en ook voor tuinbouw. Dat levert meer concurrentie.

- De agrarische grondprijzen zijn een gemiddelde over de jaren 2012-augustus 2016 in verband met het aantal waarnemingen. Verschillen tussen jaren worden hierdoor weggemiddeld. In Bouwhoek en Hogeland bijvoorbeeld lag de gemiddelde grondprijs in de eerste drie kwartalen van 2016 op 59.000 euro per ha (tegenover gemiddeld 49.000 euro per ha in de periode 2012-augustus 2016). 


\section{Verantwoording}

\section{Agrarische grondprijs}

De agrarische grondprijs is de prijs van vrij beschikbare landbouwgrond gekocht door agrariërs. Aan de basis van de berekening van de grondprijs staan de transacties in het eigendomsregister van het Kadaster, aangevuld met informatie over de agrarische sector. Voor het bepalen van de agrarische grondprijs zijn de verhandelde percelen op de volgende kenmerken geselecteerd:

- koper heeft een landbouwbedrijf

- grasland, bouwland, snijmais

- soort overdracht is koop-verkoop

- zakelijk recht is volle eigendom

- geen opstallen

- geen reguliere pachtovereenkomst of erfpacht

- geen familierelatie

- oppervlak perceel groter dan 0,25 ha

- de koopsom is groter dan 1 euro.

Verhandelde percelen met extreem hoge en lage prijzen zijn volgens een statistische methodiek uitgesloten.

\section{Indeling grondsoorten}

Grofweg worden er in Nederland 280 verschillende bodems onderscheiden. Deze zijn ingedeeld op basis van bodemopbouw, organischestofgehalte, textuur en zandgrofheid. Voor heel Nederland is op een schaal van 1:50.000 (circa 1 boring per 5 ha) de bodem in kaart gebracht en voor sommige gebieden is dit meer in detail gedaan (ruilverkavelingen, herinrichtingen).

De grondsoortenkaart in dit themabericht is een vereenvoudiging van de bodemkaart van Nederland en deelt de gronden in op basis van de aard van de bovengrond. De aard van de bovengrond wordt bepaald door twee belangrijke eigenschappen, het organischestofgehalte en de textuur. Textuur is de verdeling van de grootte van de bodemdeeltjes, ook wel korrelgrootte verdeling. De bodemdeeltjes worden ingedeeld in drie klassen:
1. Lutum of klei: $<2 \mu \mathrm{m}$
2. Silt: $2-50 \mu \mathrm{m}$
3. Zand: $50-2.000 \mu \mathrm{m}$

Het organischestofgehalte bepaalt of een grond als veen of moerig op zand wordt ingedeeld. Voor de categorie moerig op zand is de veenlaag (of moerige lag) dunner dan $40 \mathrm{~cm}$. De onderstaande tabel geeft een overzicht van de indeling van de hoofdgrondsoorten.

Indeling hoofdgrondsoorten

\begin{tabular}{|c|c|c|c|c|c|c|c|c|}
\hline & Veen & $\begin{array}{r}\text { Moerig op } \\
\text { zand a) }\end{array}$ & Zand & Leem & $\begin{array}{l}\text { Lichte } \\
\text { zavel }\end{array}$ & $\begin{array}{r}\text { Zware } \\
\text { zavel }\end{array}$ & $\begin{array}{r}\text { Lichte } \\
\text { klei }\end{array}$ & $\begin{array}{r}\text { Zware } \\
\text { klei }\end{array}$ \\
\hline Lutum (\%) & & & & & $8-17,5$ & $17,5-25$ & $25-35$ & $35-45$ \\
\hline Silt (\%) & & & $<50$ & $>50$ & & & & \\
\hline Zand $(\%)$ & & & $>50$ & $<50$ & & & & \\
\hline Organisch stof $(\%)$ & $>15 / 30$ & $\mathrm{a}$ & $<15$ & $<15$ & $<15$ & $<18$ & $<20$ & $<22,5$ \\
\hline
\end{tabular}

a) $>15 / 30 \%$ organischestofgehalte en moerige bovengrond $<40 \mathrm{~cm}$. 